\title{
The TREAT Study — Trial or Tribulation?
}

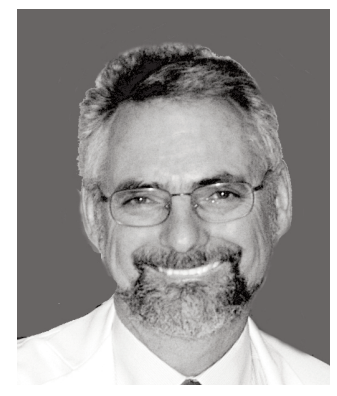

At the first Park City conference in 1976 there were 66 pediatric rheumatologists. "State of the art" ${ }^{1}$ was simply a series of reports of the clinical experience of each center. There were no randomized or multicenter collaborative trials. The "control group" was each center's past experience at a time when the control of childhood arthritis was elusive, and myochrysine and acetylsalicylic acid were the mainstays of therapy for arthritis, with corticosteroids as an undesirable, but sometimes necessary, fallback. Now there are both many more medications to choose from and over 300 American Board of Pediatrics-certified pediatric rheumatologists, with many more practicing in other countries. The Internet has made possible rapid interaction and collaborative studies involving institutions around the world. Yet with all these advances, funding for studies of children with rheumatic disease and children who can be entered into investigational studies remain scarce and precious resources. Thus, it is vitally important that studies be well thought out and be of importance to both clinical practice and the welfare of the children, without placing them at unnecessary risk. The original TRial of Early Aggressive Therapy in polyarticular juvenile idiopathic arthritis (TREAT) study ${ }^{2}$ and a followup report, published in this issue of The Journal ${ }^{3}$, fail this test.

Pediatric rheumatologists have labored long and hard to eliminate the use of corticosteroids in the care of children with arthritis because, even with short-term use, they can result in infection and can affect self-image, growth, metabolism, and bone structure. In clinical experience, the biologic agents such as those that block tumor necrosis factor- $\alpha$ (TNF- $\alpha$ ) have all but eliminated the need for corticosteroids in children who do not have systemic onset juvenile idiopathic arthritis. When the major question in the mind of practicing clinicians is "Will the early addition of a TNF- $\alpha$ blocking agent provide superior results either alone or in combination with methotrexate (MTX)?", why were corticosteroids in a high dose $(0.5 \mathrm{mg} / \mathrm{kg}$ up to $60 \mathrm{mg})$ added to the initial regimen of the only arm with a TNF- $\alpha$ blocking agent? Doing so prevented evaluation of the true benefits of either the corticosteroids or the etanercept used. It is highly unlikely that any practicing pediatric rheumatologist would simultaneously initiate treatment with both corticosteroids and a TNF- $\alpha$ blocking agent prior to this study, and hopefully none will do so now.

We needed and continue to need a study evaluating the early use of biologic agents with or without MTX. The only possible rationale for the inclusion of corticosteroids in the TREAT study is reference to the BeSt studies in adults ${ }^{4}$, which showed improved results with the use of corticosteroids, but which were done prior to the widespread availability of biologics. In their followup summary in 2009, the BeSt study authors recommended biologics or corticosteroids, not both ${ }^{3}$.

The time, money, and effort of the investigators and the funding agencies - and most importantly the children and their families - are far too valuable to tolerate waste. Those responsible for initiating clinical trials must be thoughtful about the clinical relevance of their studies for the practicing pediatric rheumatologist, rather than the easy copying of studies done by the adult rheumatology community. When the studies are accomplished only later and with smaller numbers in children, they are of little clinical value. The inclusion of corticosteroids in this study without an arm evaluating biologics alone and/or in combination of MTX failed to provide the answers that practicing pediatric rheumatologists were seeking.

THOMAS J.A. LEHMAN, MD, Chief, Division of Pediatric Rheumatology, Hospital for Special Surgery; and Professor of Clinical Pediatrics, Weill Medical College of Cornell University, New York, New York, USA.

Address correspondence to Dr. Lehman, Hospital for Special Surgery, 535 E. 70th St., New York, New York 10021, USA.

E-mail: goldscout@aol.com

\section{REFERENCES}

1. Proceedings of the First ARA Conference on the Rheumatic Diseases of Childhood. Park City, Utah, March 22-25, 1976. Arthritis Rheum 1977;20 Suppl.

\section{See Clinically inactive disease in new-onset JIA, page 1163}


2. Wallace CA, Giannini EH, Spalding SJ, Hashkes PJ, O'Neil KM, Zeft AS, et al; Childhood Arthritis and Rheumatology Research Alliance. Trial of early aggressive therapy in polyarticular juvenile idiopathic arthritis. Arthritis Rheum 2012;64:2012-21.

3. Wallace CA, Giannini EH, Spalding SJ, Hashkes PJ, O'Neil KM, Zeft AS, et al. Clinically inactive disease in a cohort of children with new-onset polyarticular juvenile idiopathic arthritis treated with early aggressive therapy: time to achievement, total duration, and predictors. J Rheumatol 2014;41:1163-70.

4. Klarenbeek NB, Allaart CF, Kerstens PJ, Huizinga TW, Dijkmans BA. The BeSt story: on strategy trials in rheumatoid arthritis. Curr Opin Rheumatol 2009;21:291-8.

J Rheumatol 2014;41:1038-9; doi:10.3899/jrheum.140404 